\title{
Kesahan dan Kebolehpercayaan Instrumen Penghayatan Akidah
}

\author{
Validity and Reliability of the Religious Belief Instrument
}

\author{
NORSALEHA MOHD*. SALLEH, AB. HALIM TAMURI \& SALLEH AMAT¹
}

\begin{abstract}
This article discussed the construct validity and reliability of faith appreciation questionnaire. The instrument was developed based on past literature, expert opinion and research objectives. Expert interview has been done to validate the instrument construct and content while Cronbach's alpha coefficient has been used to identify the value and level of internal consistency. Result shows the overall value of Cronbach's alpha for the instrument is 0.868. However, each construct show a different value of reliability such as moderate level in understanding, $\alpha=$ 0.662; very high value of feeling, $\alpha=0.910$ and high in practicing, $\alpha=0.830$. Based on the result, some improvements on the instrument item need to be done for the next research.
\end{abstract}

Keywords: faith appreciation, instrument, reliability, religiosity, validity

Dalam konteks sosial, akidah merupakan tunjang yang berperanan melahirkan individu yang mempunyai keyakinan yang tinggi kepada Allah s.w.t. dan seterusnya mampu membentuk jiwa yang tenang dan rohani yang seimbang dengan amalan hidup dan tingkah laku. Ini berikutan sifat dan nilai yang ada dalam akidah Islam itu sendiri menekankan aspek-aspek keimanan, kerohanian, keilmuan, penghayatan dan amalan bagi melahirkan individu yang seimbang emosi, rohani dan akalnya dengan amalan dan tingkah laku fizikalnya (Sabiq 2003). Keruntuhan nilai akidah dalam diri seseorang bukan sahaja menjadi ancaman kepada kesejahteraan diri dan masyarakat (al-Qaradawi 2005) malah turut menjadi punca sebenar kepada kelemahan emosi dan spiritual seseorang yang mengakibatkan berlaku perkara-perkara yang tidak diingini seperti kecenderungan membunuh diri serta kemurungan (al-Kindi 1980).

\section{Ulasan Kepustakaan}

Permasalahan penghayatan akidah dalam kalangan pelajar telah dibincangkan oleh Yahya (2004) yang melihat penglibatan golongan remaja dalam aktiviti black metal boleh merosakkan akidah. Gejala black metal sering dikaitkan dengan aliran muzik liar, brutal dan songsang serta mengandungi pemujaan syaitan yang berupaya memesongkan akidah dan menjerumuskan golongan remaja ke lembah keruntuhan akhlak yang serius (Hazman 2011; Ridhuan Tee 2009; Yahya 2004; Wan Noor Afizatun 2003). Kumpulan ini sering melakukan aktiviti yang memperlecehkan akidah Islam seperti menghina Rasulullah s.a.w. (Hazman 2011) serta memijak dan membakar al-Quran al-Karim (Yahya 2004; Wan Noor Afizatun 2003). Selain itu, ahli kumpulan black metal juga sering dikatakan terlibat dengan kegiatan negatif lain seperti melakukan hubungan seks bebas, meminum arak, menghisap dadah, penyalahgunaan pil khayal serta mengamalkan cara hidup yang bertentangan dengan norma masyarakat (Yahya 2004; Wan Noor Afizatun 2003).

\footnotetext{
${ }^{1}$ Norsaleha Mohd. Salleh*(Corresponding author), M.A., Lecturer at Islamic Academy, Kolej Universiti Islam Selangor, 45000 KAJANG, Selangor, Malaysia. Email: ummu_uthman@yahoo.com; Abd Halim Tamuri, Ph.D., Assoc. Prof. at Dept. of Educational Leadership and Policy, Faculty of Education, Universiti Kebangsaan Malaysia, 43600 BANGI, Selangor, Malaysia. Email: abhalim@ukm.my; Salleh Amat, Ph.D., Assoc. Prof. at Department of Foundation of Education, Faculty of Education, Universiti Kebangsaan Malaysia, 43600 BANGI, Selangor, Malaysia. Email: sallehba@ukm.my.
} 
Kemerosotan akhlak dalam kalangan remaja ini hanya boleh diatasi melalui kekuatan akidah dan hubungan yang berterusan dengan Allah Taala (al-Qaradawi 2005; Hamka 2003; Ary 2002). Kekuatan akidah merupakan satu daripada empat kekuatan asas yang harus dikuasai oleh remaja bagi membersihkan emosi, fikiran dan perlakuan daripada melakukan perkaraperkara yang bertentangan dengan kehendak Islam dan tidak bermanfaat. Menurut Aulia (1970) pengetahuan tentang kesyumulan agama Islam terutamanya akidah Islam dapat membantu mereka yang mengalami kerisauan atau anxiety daripada terus berhadapan dengan situasi yang mengganggu jiwa mereka. Untuk mengenalpasti tahap penghayatan akidah golongan remaja, satu instrumen untuk mengukur penghayatan akidah remaja perlu dibina dan diuji kepada golongan ini.

Munawar (2009) telah membangunkan satu inventori Pengetahuan Akidah yang mengukur tahap pengetahuan pelajar terhadap akidah Islam dan hubungannya dengan akhlak pelajar sekolah menengah di Malaysia. Manakala Azma (2006) pula telah membangunkan Skala Penghayatan Pendidikan Islam Pelajar yang bertujuan mengukur tahap penghayatan pendidikan Islam pelajar sekolah menengah di Malaysia. Inventori Pengetahuan Akidah oleh Munawar (2009) hanya mengukur tahap pengetahuan akidah pelajar, manakala Skala Penghayatan Pendidikan Islam oleh Azma (2006) pula mengukur tahap penghayatan Pendidikan Islam pelajar. Hal ini memerlukan pengkaji membuat pengubahsuaian mengikut objektif kajian pengkaji iaitu mengenalpasti tahap penghayatan akidah pelajar Sekolah Menengah Kebangsaan di Malaysia. Bagi tujuan pengubahsuaian item pengkaji merujuk kepada al-Ghazali (t.th. 2005), Sayyid Sabiq (2003) dan Naim Yasin (1983). Pengkaji menggunakan prosedur yang sama bagi pembinaan item dengan mendapatkan kesahan gagasan dan kandungan daripada pakar yang dilantik. Instrumen Penghayatan Akidah Pelajar dibina bagi mengukur tahap penghayatan akidah pelajar Sekolah Menengah Kebangsaan di Malaysia. Instrumen ini melibatkan tiga domain utama penghayatan akidah iaitu kefahaman, perasaan dan amalan.

\section{Objektif Kajian}

Objektif kajian ialah untuk menentukan kebolehpercayaan dan kesahan gagasan dan kandungan bagi soal selidik penghayatan akidah. Secara khusunya, kajian ini bertujuan untuk: 1 . Menentukan kesesuaian item dengan konstruk penghayatan akidah melalui kesahan pakar, dan 2. Menentukan nilai kebolehpercayaan instrument melalui analisis pekali alpha.

\section{Pembinaan Instrumen Penghayatan Akidah}

Kajian literatur dan temubual pakar akidah Islam dijalankan bagi mendapatkan definisi konseptual bagi penghayatan akidah. Berdasarkan kajian literatur, objektif kurikulum Pelajaran Pendidikan Islam KBSM T1-T3 dan pandangan pakar akidah Islam, pengkaji mengemukakan definisi konseptual bagi penghayatan akidah sebagai berikut:

Proses seseorang menjiwai dan berpegang teguh dengan isi kandungan akidah dengan penuh kefahaman, perasaan serta diikuti dengan amal perbuatan yang selari dengan tuntutan iman.

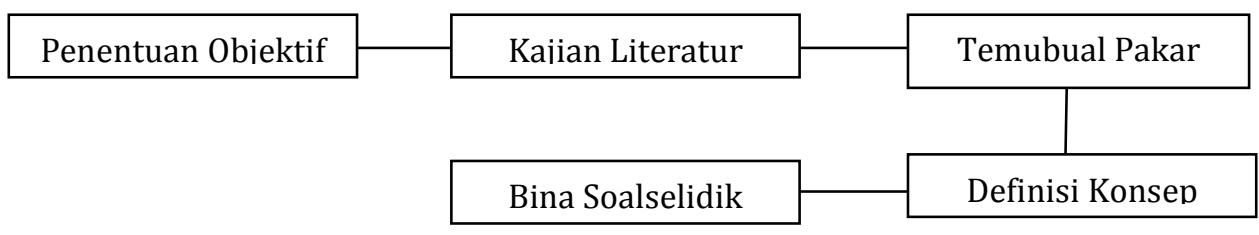

Rajah 1.1: Pembinaan Instrumen Kajian 
Rajah 1.1 menunjukkan prosedur pembinaan item yang bermula dengan penentuan objektif kajian, membuat kajian literatur dan mendapatkan pandangan pakar bagi menentukan definisi konseptual bagi pemboleh ubah penghayatan akidah. Selepas memperoleh definisi konseptual bagi penghayatan akidah, pengkaji mula membina item dengan merujuk kepada alGhazali (2005), Sabiq (2003), Azma (2006) dan Munawar (2009). Menurut al-Qaradawi (2005) penghayatan akidah itu berlaku apabila keimanan seseorang kepada Allah s.w.t. meresap dalam hati dan perasaan, menguasai akal dan fikiran sehingga mencetuskan perasaan bertanggungjawab untuk melaksanakan perintah Allah s.w.t. dan menyuruh orang lain juga melakukan kebaikan. Manakala HAMKA (2003) pula berpendapat akidah itu ialah kesepaduan antara kepercayaan dan penyerahan diri, pengakuan hati dan perbuatan. Menurut Mohamad Sulaiman (1988) akidah Islam itu ialah kepercayaan dan keimanan kepada hakikat dan nilai yang mutlak, yang tetap dan kekal, yang pasti dan hakiki lagi qudus dan suci seperti yang diwajibkan oleh Islam iaitu kepercayaan yang tersimpul kukuh dan teguh dalam jiwa sehingga tidak mungkin akan terhurai atau terputus walau oleh apa pun jua keadaan dan suasana. Oleh sebab itu, Ab. Halim (2008), Azhar (2006), Mohd. Arip (1998) dan Hasan (1983) berpendapat, pendidikan akidah Islam amat memerlukan kepada pendekatan pengajaran dan pembelajaran yang bukan sahaja berupaya memindahkan ilmu pengetahuan dan teori, tetapi juga mampu meningkatkan penghayatan dan amalan dalam kehidupan seharian.

Temubual bersama dua orang pakar akidah telah dijalankan untuk mengesahkan tiga jenis konstruk yang digunakan untuk membina item bagi penghayatan akidah. Hasil daripada perbincangan, pakar pertama berpendapat penghayatan akidah adalah tahap keyakinan terhadap rukun iman yang tinggi. Tiga perkara utama dalam rukun iman ialah ketuhanan, kenabian dan akhirat. Keyakinan kepada Tuhan akan melahirkan hamba yang takut dan berbudi pekerti baik. Keyakinan kepada Nabi s.a.w. akan membawa hamba itu cuba untuk mengikut cara dan qudwah Nabi. Keyakinan kepada akhirat akan melahirkan hamba yang ingat hari pembalasan. Beliau juga merujuk pandangan al-Ghazali dalam mengkategorikan penghayatan kepada tiga konstruk utama iaitu kefahaman, perasaan dan amalan. Manakala pakar kedua berpendapat penghayatan adalah peringkat kedua selepas kefahaman. Untuk menghayati akidah, seseorang perlu melalui proses kefahaman. Penghayatan boleh dilihat dari aspek kesan dalam tindak tanduk seharian serta dalam keadaan susah dan senang. Beliau juga bersetuju bahawa penghayatan memerlukan kepada aspek kefahaman, perasaan dan amalan seseorang. Berdasarkan kepada kajian literatur dan temu bual pakar akidah, pengkaji merumuskan konstruk bagi penghayatan akidah ialah kefahaman, perasaan dan amalan (sila rujuk rajah 1.2).

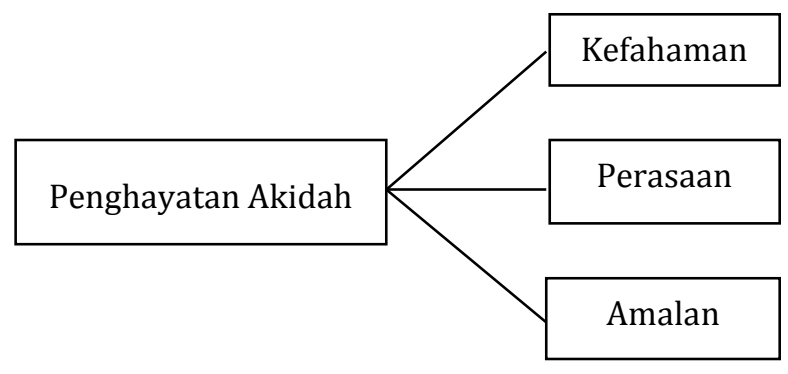

Rajah 1.2: Konstruk Penghayatan Akidah

Walau bagaimanapun, item yang dibangunkan oleh Stoner dan rakan-rakan (2011) menggunakan dua langkah sahaja iaitu membina skala item itu sendiri dan mendapatkan penilaian daripada dua orang pakar sahaja. Justifikasi yang diberikan oleh Stoner dan rakanrakannya adalah untuk mengenalpati item yang mewakili maksud bagi setiap dimensi dan mengekalkan keaslian item berdasarkan sumber literatur yang dirujuk. Namun begitu, pengkaji masih menggunakan kaedah yang biasa digunapakai oleh ramai pengkaji dengan meletakkan asas pembinaan item kepada model dan pandangan ulama, pendapat pakar dan matlamat Kurikulum Pendidikan Islam (KBSM) itu sendiri. 


\section{Kesahan Pakar}

Bagi tujuan mendapat kesahan gagasan dan kandungan, pengkaji menggunakan pendapat Gable dan Wolf (1993) yang mencadangkan penilaian kepada kandungan hendaklah berbentuk positif dan negatif. Kesahan kandungan ini dijalankan bagi memastikan item yang dibina mewakili konstruk yang disenaraikan (Noraini 2010; Sidek 2002). Kajian ini melantik sembilan orang pakar yang mempunyai pengetahuan tentang subjek yang dikaji. Ini selari dengan pandangan Gable dan Wolf (1993) yang mencadangkan lima orang pakar yang mempunyai pengetahuan mengenai subjek yang dikaji.

Pengkaji telah berjumpa dengan semua panel yang dilantik dan menerangkan tentang latar belakang kajian, definisi konsep dan operasional konstruk dan tugasan yang perlu dilaksanakan. Mereka telah diberikan borang penilaian, diminta membuat pembetulan dan memberi komentar dan cadangan kepada item yang kurang menepati kehendak konstruk. Berdasarkan borang ini mereka dikehendaki mengesahkan perkara berikut:

i- Konstruk penghayatan akidah

ii- Item yang mewakili bagi setiap konstruk penghayatan akidah

iii- Kenyataan benar dan salah (positif dan negatif) dalam konteks ilmu Islam

\section{Ujian Rintis}

Instrumen Penghayatan Akidah telah dirintiskan ke atas 100 orang pelajar Tingkatan Empat di dua buah Sekolah Menengah Kebangsaan (SMK Seafield dan SMK Abd. Jalil) di Daerah Hulu Langat pada awal September 2012. Pada waktu itu sekolah tersebut akan mula menjalani peperiksaan PMR dan akhir tahun pada bulan Oktober. Bagi mengejar masa masa yang ada sebelum peperiksaan bermula, pentadbiran soal selidik di SMK Abd.Jalil dijalankan sendiri oleh pengkaji mana kala pentadbiran di SMK Seafield dijalankan oleh guru Pendidikan Islam di sekolah tersebut. Penerangan kepada guru Pendidikan Islam yang terlibat telah diberikan oleh pengkaji bagi sekolah yang tidak ditadbirkan oleh pengkaji. Sekolah SMK adalah sekolah yang menjadi sampel dalam kajian sebenar pengkaji. Pemilihan responden ditentukan oleh pihak sekolah setelah berbincang dengan guru Pendidikan Islam.

Seramai 51 orang responden (51\%) adalah responden lelaki mana kala 49 orang lagi adalah responden perempuan (49\%). Dari segi aliran pula, responden aliran sains adalah 5 orang (5\%) berbanding responden bukan sains seramai 95 orang (95\%). Seramai 12 orang (12\%) mendapat gred A dalam Pendidikan Islam dalam PMR, 39 orang (39\%) responden mendapat gred B, 43 orang responden (43\%) mendapat gred C, empat orang responden dan seorang responden mendapat gred E. Kesemua pelajar lulus ujian PAFA peringkat PMR (sila rujuk jadual 1.1).

Jadual 1.1: Maklumat Profil Responden dalam Ujian Rintis

\begin{tabular}{llrr}
\hline Profil & Kategori & Kekerapan & Peratusan \\
\hline Jantina & L & 51 & 51 \\
\multirow{3}{*}{ Sekolah } & P & 49 & 49 \\
& SMK Seafield & 50 & 50 \\
\multirow{2}{*}{ Aliran } & SMK Abd. Jalil & 50 & 50 \\
& Sains & 5 & 5 \\
& Bukan Sains & 95 & 95 \\
& A & 12 & 12 \\
& B & 39 & 39 \\
& C & 43 & 43 \\
PAFA & D & 4 & 4 \\
& E & 1 & 1 \\
& Lulus & 100 & 100 \\
& Gagal & 0 & 0 \\
\hline
\end{tabular}


Secara keseluruhan pelajar di kedua-dua buah sekolah telah mengambil masa antara 3045 minit bagi melengkapkan kertas soal selidik. Di kedua-dua buah sekolah kajian, pelajar tidak menghadapi masalah memahami arahan dan cara menjawab soal selidik. Di SMK Abdul Jalil, terdapat dua orang sampel tidak memahami perkataan tadarus (B89) dan mencadangkan kepada pengkaji agar ditukar kepada perkataan membaca.

\section{Kesahan Konstruk dan Kandungan}

Keputusan penilaian pakar telah dikumpulkan dan dianalisis. Jadual 1.2 menunjukkan penilaian pakar secara keseluruhan kepada pembentukan konstruk dan item soal selidik. Enam daripada sembilan pakar mencadangkan agar jumlah item dikurangkan. Berdasarkan perbincangan dengan pakar, pengkaji mengambil keputusan untuk membuang item yang didapati kurang menepati konstruk dan item yang mempunyai makna yang hampir sama. Hanya item yang mempunyai $100 \%$ persetujuan sahaja yang diterima. Terdapat item yang dipersetujui oleh semua pakar tetapi disarankan oleh sebahagian pakar agar dimurnikan pernyataannya supaya lebih mudah difahami maksudnya. Sebanyak 34 item telah dibuang daripada 124 item yang melibatkan 13 item bagi konstruk kefahaman, 10 item bagi konstruk perasaan dan 11 item bagi konstruk amalan (sila rujuk jadual 1.3). Sebanyak 30 item telah diperbaiki yang melibatkan 9 item dari konstruk kefahaman, 12 item dari konstruk perasaan dan 9 item dari konstruk amalan (sila rujuk jadual 1.4). Dengan itu jumlah item yang tinggal selepas semakan ialah sebanyak 90 item.

Jadual 1.2: Penilaian Keseluruhan Pakar

\begin{tabular}{|c|c|c|c|c|c|c|c|c|c|}
\hline & P1 & P2 & P3 & P4 & P5 & P6 & P7 & P8 & P9 \\
\hline Ketepatan penggunaan konstruk. & ok & ok & ok & ok & ok & ok & ok & ok & ok \\
\hline Format instrumen kajian. & ok & ok & ok & ok & ok & ok & ok & ok & baiki \\
\hline Kejelasan makna setiap item. & baiki & baiki & ok & baiki & baiki & ok & baiki & baiki & baiki \\
\hline $\begin{array}{l}\text { Kesesuaian bahasa yang } \\
\text { digunakan. }\end{array}$ & ok & ok & ok & ok & ok & ok & ok & ok & ok \\
\hline Kesesuaian saiz tulisan. & ok & ok & ok & ok & ok & ok & ok & ok & ok \\
\hline $\begin{array}{l}\text { Kejelasan tentang arahan yang } \\
\text { diberikan. }\end{array}$ & ok & ok & ok & ok & ok & ok & ok & ok & ok \\
\hline Penggunaan jarak tulisan. & ok & ok & ok & ok & ok & ok & ok & ok & ok \\
\hline Petunjuk bagi skala pengukuran. & ok & ok & ok & ok & ok & ok & ok & ok & ok \\
\hline Kejelasan objektif instrument. & ok & ok & ok & ok & ok & ok & ok & ok & ok \\
\hline Ulasan am. & $\begin{array}{l}\text { kurangkan } \\
\text { item }\end{array}$ & ok & ok & \multicolumn{2}{|c|}{$\begin{array}{l}\text { kurangkan } \\
\text { item }\end{array}$} & ok & \multicolumn{3}{|c|}{ kurangkan item } \\
\hline
\end{tabular}

Jadual 1.2: Item Yang Dibuang Berdasarkan Penilaian Pakar

\begin{tabular}{|c|c|c|c|}
\hline Konstruk & $\begin{array}{l}\text { No. } \\
\text { Item }\end{array}$ & Pernyataan item & Komen \\
\hline \multirow{6}{*}{ Kefahaman } & 06 & $\begin{array}{l}\text { Orang yang beriman kepada Allah tidak takut kepada } \\
\text { manusia, jin dan syaitan. }\end{array}$ & Kurang menepati konstruk. \\
\hline & 07 & $\begin{array}{l}\text { Manusia mempunyai keupayaan untuk berfikir tanpa } \\
\text { batasan. }\end{array}$ & Kurang menepati konstruk. \\
\hline & 09 & $\begin{array}{l}\text { Manusia perlu berusaha untuk memperoleh rezeki yang } \\
\text { halal. }\end{array}$ & Kurang menepati konstruk. \\
\hline & 25 & $\begin{array}{l}\text { Orang yang beriman akan dilayan dengan baik di dalam } \\
\text { kubur oleh malaikat Mungkar dan Nakir. }\end{array}$ & Kurang menepati konstruk. \\
\hline & 26 & $\begin{array}{l}\text { Orang yang derhaka akan mendapat seksaan dan azab } \\
\text { yang buruk di dalam kubur. }\end{array}$ & $\begin{array}{l}\text { Hampir sama makna } \\
\text { dengan item } 25 .\end{array}$ \\
\hline & 29 & Pada hari Kiamat seluruh alam akan musnah & Kurang menepati konstruk. \\
\hline
\end{tabular}


termasuklah langit dan bumi.

31 Beriman kepada hari Akhirat membentuk jiwa yang bertakwa kepada Allah.

32 Manusia akan diberi pembalasan yang setimpal dengan perbuatannya sewaktu di dunia.

33 Kisah kehidupan di alam kubur sangat menakutkan.

35 Semua anggota badan akan menjadi saksi pada hari akhirat.

39 Orang yang bersabar akan disayangi Allah.

41 Tiada kuasa yang boleh melawan kuasa Allah.

42 Manusia diberi kebebasan untuk memilih antara kebaikan dan keburukan.

\begin{tabular}{|c|c|c|c|}
\hline \multirow{6}{*}{ Perasaan } & 46 & $\begin{array}{l}\text { Saya merasai kasih sayang Allah setiap masa dalam } \\
\text { hidup saya. }\end{array}$ & Kurang menepati konstruk. \\
\hline & 50 & Saya merasa selamat apabila berserah kepada Allah. & Kurang menepati konstruk. \\
\hline & 57 & Saya merasa seronok apabila membaca buku sirah & Kurang menepati konstruk. \\
\hline & & Rasulullah s.a.w.. & \\
\hline & 64 & Saya merasa seronok menghafal al-Quran. & $\begin{array}{l}\text { Hampir sama makna } \\
\text { dengan item } 65 .\end{array}$ \\
\hline & 68 & $\begin{array}{l}\text { Saya merasa gembira apabila diberitahu tentang azab } \\
\text { dalam kubur. }\end{array}$ & $\begin{array}{l}\text { Hampir sama makna } \\
\text { dengan item } 73 .\end{array}$ \\
\hline \multirow{5}{*}{ Perasaan } & 69 & $\begin{array}{l}\text { Saya sentiasa berdoa diselamatkan dari seksaan dalam } \\
\text { kubur. }\end{array}$ & $\begin{array}{l}\text { Hampir sama makna } \\
\text { dengan item } 72 .\end{array}$ \\
\hline & 72 & Saya berharap diselamatkan dari seksaan azab kubur. & $\begin{array}{l}\text { Hampir sama makna } \\
\text { dengan item } 71 .\end{array}$ \\
\hline & 75 & $\begin{array}{l}\text { Saya berharap dapat meniti titian Sirat di akhirat kelak } \\
\text { dengan mudah. }\end{array}$ & Kurang menepati konstruk. \\
\hline & 79 & $\begin{array}{l}\text { Saya berazam untuk meningkatkan keimanan saya } \\
\text { kepada Allah s.w.t. }\end{array}$ & Kurang menepati konstruk. \\
\hline & 82 & $\begin{array}{l}\text { Saya merasai kebenaran firman Allah yang menyatakan } \\
\text { semakin kamu bersyukur semakin banyak Allah bagi } \\
\text { nikmatNya kepadamu. }\end{array}$ & Kurang menepati konstruk. \\
\hline \multirow{11}{*}{ Amalan } & 87 & $\begin{array}{l}\text { Saya sentiasa berfikir tentang ciptaan Allah s.w.t. yang } \\
\text { terdapat di sekeliling saya. }\end{array}$ & $\begin{array}{l}\text { Hampir sama makna } \\
\text { dengan item } 04 .\end{array}$ \\
\hline & 88 & $\begin{array}{l}\text { Saya memohon perlindungan Allah s.w.t. daripada } \\
\text { gangguan jin dan syaitan. }\end{array}$ & Kurang menepati konstruk. \\
\hline & 89 & Saya berdoa agar dilindungi dari seksaan api neraka. & $\begin{array}{l}\text { Hampir sama makna } \\
\text { dengan item } 69 .\end{array}$ \\
\hline & 90 & $\begin{array}{l}\text { Saya mengasihi orang lain agar Allah s.w.t. akan } \\
\text { mengasihi saya. }\end{array}$ & Kurang menepati konstruk \\
\hline & 93 & Saya membaca doa setiap kali hendak makan. & Kurang menepati konstruk \\
\hline & 98 & $\begin{array}{l}\text { Saya menceritakan tentang kisah malaikat kepada orang } \\
\text { lain. }\end{array}$ & $\begin{array}{l}\text { Hampir sama makna } \\
\text { dengan item } 96\end{array}$ \\
\hline & 101 & $\begin{array}{l}\text { Saya banyak membaca kisah para nabi termasuk kisah } \\
\text { Nabi Muhamad s.a.w.. }\end{array}$ & Kurang menepati konstruk. \\
\hline & 104 & $\begin{array}{l}\text { Saya berceritakan kisah para Nabi Mohamad kepada } \\
\text { orang lain. }\end{array}$ & Kurang menepati konstruk. \\
\hline & 113 & Saya sentiasa membaca tentang hari qiamat. & Kurang menepati konstruk. \\
\hline & 115 & Saya berdoa agar diringankan azab kubur. & $\begin{array}{l}\text { Hampir sama makna } \\
\text { dengan item } 96 .\end{array}$ \\
\hline & 116 & Saya berdoa agar dijauhi azab api neraka. & $\begin{array}{l}\text { Hampir sama makna } \\
\text { dengan item } 96\end{array}$ \\
\hline
\end{tabular}

Kurang menepati konstruk.

Hampir sama makna dengan item 28.

Hampir sama makna dengan item 34.

Hampir sama makna dengan item 30 .

Hampir sama makna dengan item 80.

Kurang menepati konstruk. Hampir sama makna dengan item 37.

Kurang menepati konstruk.

Kurang menepati konstruk.

Hampir sama makna dengan item 65.

dengan item 72

dengan item 71

Kurang menepati konstruk

Kurang menepati konstruk

Kurang menepati konstruk.

ma makna dengan item 04

Hampir sama makna dengan item 69

Kurang menepati konstruk

Hampir sama makna dengan item 96

Kurang menepati konstruk.

Kurang menepati konstruk.

Hampir sama makna

Hampir sama makna dengan item 96 


\section{Vol. 3: (June) 2013}

Jadual 1.3: Item Yang Diperbaiki Berdasarkan Saranan Pakar

\begin{tabular}{|c|c|c|c|}
\hline Konstruk & Item & Item Asal & Item setelah dibaiki \\
\hline \multirow{12}{*}{ Kefahaman } & 02 & $\begin{array}{l}\text { Aqidah yang benar mengajak manusia } \\
\text { menyembah Allah s.w.t. sahaja. }\end{array}$ & $\begin{array}{l}\text { Aqidah yang benar menyebabkan manusia } \\
\text { menunaikan solat. }\end{array}$ \\
\hline & 03 & $\begin{array}{l}\text { Manusia perlu meletakkan matlamat } \\
\text { hidupnya untuk mengabdikan diri kepada } \\
\text { Allah s.w.t. }\end{array}$ & $\begin{array}{l}\text { Matlamat hidup manusia untuk } \\
\text { mengabdikan diri kepada Allah s.w.t. }\end{array}$ \\
\hline & 11 & $\begin{array}{l}\text { Manusia perlu mengetahui tentang sifat } \\
\text { malaikat yang tunduk dan bertasbih kepada }\end{array}$ & $\begin{array}{l}\text { Tugas malaikat ialah bertasbih kepada } \\
\text { Allah s.w.t. }\end{array}$ \\
\hline & & Allah s.w.t. & \\
\hline & 12 & $\begin{array}{l}\text { Manusia perlu mengetahui tentang adanya } \\
\text { malaikat yang sentiasa memohon } \\
\text { keampunan untuk orang yang beriman } \\
\text { kepada Allah. }\end{array}$ & $\begin{array}{l}\text { Malaikat sentiasa memohon keampunan } \\
\text { untuk orang yang beriman kepada Allah. }\end{array}$ \\
\hline & 13 & $\begin{array}{l}\text { Malaikat mempunyai sifat yang sama seperti } \\
\text { manusia. }\end{array}$ & $\begin{array}{l}\text { Malaikat sentiasa mengawasi tingkah laku } \\
\text { manusia. }\end{array}$ \\
\hline & 14 & $\begin{array}{l}\text { Rasul adalah seorang lelaki yang } \\
\text { diwahyukan Allah untuk menyampaikan } \\
\text { syariat kepada manusia. }\end{array}$ & $\begin{array}{l}\text { Rasulullah s.a.w. bertugas menyampaikan } \\
\text { ajaran Islam kepada manusia. }\end{array}$ \\
\hline & 16 & $\begin{array}{l}\text { Allah s.w.t. akan memberi pahala kepada } \\
\text { sesiapa yang mengikut sunah Rasulullah } \\
\text { s.a.w. }\end{array}$ & $\begin{array}{l}\text { Orang yang mengikut cara hidup } \\
\text { Rasulullah s.a.w. akan diberi pahala. }\end{array}$ \\
\hline & 19 & $\begin{array}{l}\text { Nabi Muhamad s.a.w. diutuskan untuk kaum } \\
\text { Quraisy sahaja. }\end{array}$ & $\begin{array}{l}\text { Nabi Muhamad s.a.w. diutuskan kepada } \\
\text { semua manusia. }\end{array}$ \\
\hline & 21 & $\begin{array}{l}\text { Manusia perlu mengambil al-Quran sebagai } \\
\text { petunjuk dan panduan hidup. }\end{array}$ & $\begin{array}{l}\text { Al-Quran adalah kitab yang boleh menjadi } \\
\text { panduan hidup manusia. }\end{array}$ \\
\hline & 38 & $\begin{array}{l}\text { Manusia perlu bersyukur dengan nikmat } \\
\text { Allah. }\end{array}$ & $\begin{array}{l}\text { Manusia perlu berusaha untuk menjadi } \\
\text { baik. }\end{array}$ \\
\hline & 40 & $\begin{array}{l}\text { Allah Maha Berkuasa menentukan segala- } \\
\text { galanya. }\end{array}$ & $\begin{array}{l}\text { Manusia bertanggungjawab dengan setiap } \\
\text { perbuatan yang dia lakukan. }\end{array}$ \\
\hline \multirow{5}{*}{ Perasaan } & 45 & $\begin{array}{l}\text { Saya merasai kehebatan kuasa Allah s.w.t. } \\
\text { dalam berbagai-bagai kejadian di alam ini. }\end{array}$ & $\begin{array}{l}\text { Saya menyedari kehebatan kekuasaan } \\
\text { Allah s.w.t. dalam penciptaan manusia. }\end{array}$ \\
\hline & 47 & $\begin{array}{l}\text { Saya merasakan semua perkara yang } \\
\text { dilakukan kerana Allah adalah ibadat. }\end{array}$ & $\begin{array}{l}\text { Saya merasa risau selagi belum } \\
\text { menunaikan solat. }\end{array}$ \\
\hline & 53 & $\begin{array}{l}\text { Saya gembira apabila mengetahui Allah } \\
\text { mengutuskan malaikat untuk menjaga saya } \\
\text { dan manusia yang lain. }\end{array}$ & $\begin{array}{l}\text { Saya merasa seronok apabila mendapat } \\
\text { ilham untuk berbuat baik. }\end{array}$ \\
\hline & 55 & $\begin{array}{l}\text { Saya gerun apabila disebut Malaikat } \\
\text { Izrail boleh datang bila-bila masa untuk } \\
\text { mencabut nyawa. }\end{array}$ & $\begin{array}{l}\text { Saya gerun apabila teringat kepada } \\
\text { kematian yang semakin dekat. }\end{array}$ \\
\hline & 58 & $\begin{array}{l}\text { Saya seronok mendengar kisah para Nabi } \\
\text { dan Rasul. }\end{array}$ & $\begin{array}{l}\text { Saya berbangga menjadi umat Nabi } \\
\text { Muhamad s.a.w.. }\end{array}$ \\
\hline \multirow{7}{*}{ Perasaan } & 61 & $\begin{array}{l}\text { Saya berazam untuk mencontohi akhlak } \\
\text { Rasulullah s.a.w.. }\end{array}$ & $\begin{array}{l}\text { Saya menyedari akhlak Rasulullah s.a.w. } \\
\text { merupakan contoh terbaik. }\end{array}$ \\
\hline & 63 & $\begin{array}{l}\text { Saya gembira apabila melihat orang } \\
\text { bersembang sewaktu ayat al-Quran dibaca. }\end{array}$ & $\begin{array}{l}\text { Saya menyedari perbuatan bermain-main } \\
\text { ketika membaca al-Quran adalah dilarang. }\end{array}$ \\
\hline & 67 & $\begin{array}{l}\text { Saya merasa kagum kepada orang yang } \\
\text { berjaya menghafal al-Quran. }\end{array}$ & $\begin{array}{l}\text { Saya menyedari tentang peranan al-Quran } \\
\text { melahirkan pelajar yang berjaya. }\end{array}$ \\
\hline & 73 & $\begin{array}{l}\text { Saya merasa gerun melihat tanda-tanda } \\
\text { awal qiamat telah berlaku. }\end{array}$ & $\begin{array}{l}\text { Saya menyedari bahawa tanda-tanda awal } \\
\text { hari kiamat telah berlaku. }\end{array}$ \\
\hline & 74 & $\begin{array}{l}\text { Saya merasa takut Allah s.w.t. menjadikan } \\
\text { neraka untuk orang yang derhaka. }\end{array}$ & $\begin{array}{l}\text { Saya menyedari Allah s.w.t. menyediakan } \\
\text { neraka untuk orang yang derhaka. }\end{array}$ \\
\hline & 80 & Saya bersabar dengan ketentuan Allah. & Saya akan bersabar dengan ujian Allah. \\
\hline & 81 & Saya menerima takdir Allah dengan redha. & $\begin{array}{l}\text { Saya menerima dugaan Allah s.w.t. dengan } \\
\text { redha. }\end{array}$ \\
\hline
\end{tabular}




\begin{tabular}{|c|c|c|c|}
\hline \multirow{10}{*}{ Amalan } & 91 & $\begin{array}{l}\text { Saya meminta ampun dari Allah s.w.t. di atas } \\
\text { dosa yang saya lakukan. }\end{array}$ & $\begin{array}{l}\text { Saya berusaha menjaga diri daripada } \\
\text { melakukan perkara yang boleh } \\
\text { merosakkan iman. }\end{array}$ \\
\hline & 92 & Saya bersedekah agar disayangi Allah. & $\begin{array}{l}\text { Saya sentiasa mempertingkatkan iman } \\
\text { dengan melakukan amalan sunat. }\end{array}$ \\
\hline & 100 & $\begin{array}{l}\text { Saya berusaha melaksanakan saranan hadis } \\
\text { Rasulullah s.a.w. yang saya baca. }\end{array}$ & $\begin{array}{l}\text { Saya berusaha mencontohi ciri-ciri } \\
\text { kepimpinan Rasulullah s.a.w.. }\end{array}$ \\
\hline & 103 & $\begin{array}{l}\text { Saya menjadikan akhlak Rasulullah s.a.w. } \\
\text { sebagai panduan apabila bergaul dengan } \\
\text { orang lain. }\end{array}$ & $\begin{array}{l}\text { Saya mencontohi sifat amanah Rasulullah } \\
\text { s.a.w. ketika melaksanakan } \\
\text { tanggungjawab. }\end{array}$ \\
\hline & 105 & $\begin{array}{l}\text { Saya menghadiri kuliah maghrib di surau } \\
\text { dan masjid untuk mendalami ilmu al-Quran. }\end{array}$ & $\begin{array}{l}\text { Saya mendalami ilmu al-Quran di tempat } \\
\text { lain. }\end{array}$ \\
\hline & 107 & $\begin{array}{l}\text { Saya mengkhatam al-Quran setiap bulan } \\
\text { Ramadan. }\end{array}$ & $\begin{array}{l}\text { Saya mentadarus al-Quran setiap bulan } \\
\text { Ramadan. }\end{array}$ \\
\hline & 108 & $\begin{array}{l}\text { Saya mengikuti kelas pengajian al-Quran di } \\
\text { sekolah. }\end{array}$ & $\begin{array}{l}\text { Saya mengikuti kelas Kemahiran al-Quran } \\
\text { (KKQ) di sekolah. }\end{array}$ \\
\hline & 110 & $\begin{array}{l}\text { Saya mengajar saudara dan kawan saya } \\
\text { membaca al-Quran. }\end{array}$ & $\begin{array}{l}\text { Saya mengajar orang lain membaca al- } \\
\text { Quran. }\end{array}$ \\
\hline & 111 & $\begin{array}{l}\text { Saya insaf apabila mendengar cerita } \\
\text { guru tentang syurga dan neraka. }\end{array}$ & $\begin{array}{l}\text { Saya insaf apabila mendengar cerita } \\
\text { tentang syurga dan neraka. }\end{array}$ \\
\hline & 123 & $\begin{array}{l}\text { Saya membuat persediaan untuk } \\
\text { menghadapi peperiksaan. }\end{array}$ & $\begin{array}{l}\text { Saya reda dengan keputusan peperiksaan } \\
\text { saya. }\end{array}$ \\
\hline Total & 30 & & \\
\hline
\end{tabular}

\section{Kebolehpercayaan Instrumen Penghayatan Akidah}

Kajian rintis dilaksanakan bagi mendapatkan data yang boleh membantu pengkaji memurnikan item penghayatan akidah sebelum kajian sebenar dijalankan. Gable dan Wolf (1993) berpendapat, terdapat beberapa teknik yang boleh digunakan untuk memeriksa kesahan dan kebolehpercayaaan instrumen seperti analisis faktor, analisis item dan analisis kebolehpercayaan. Analisis faktor hanya boleh dilaksanakan sekiranya jumlah responden adalah 6 hingga 10 kali ganda bilangan item. Dalam kajian ini, jumlah responden adalah 100 orang manakala bilangan item sebanyak 90. Ini bermakna analisis faktor tidak sesuai dilaksanakan. Namun begitu analisis item masih boleh dilakukan bagi mengenalpasti item yang perlu dimurnikan. Bagi memperoleh kebolehpercayaan bagi kajian rintis ini, pengkaji mengunakan teknik analisis kebolehpercayaan bagi peringkat item dan skala untuk setiap konstruk.

Data yang diperoleh daripada kajian rintis telah diproses menggunakan perisian SPSSPC versi 18. Sebelum diproses, data dibersihkan daripada sebarang kesilapan dan item negatif telah dikod semula (recode: $1=5,2=4,3=3,4=2,5=1$ ). Dalam kajian rintis ini sebanyak lima item telah dibentuk secara negatif (B19, B55, B60, B87 dan B88). Pengkaji menggunakan arahan analisis kebolehpercayaan bagi mendapatkan nilai pekali alpha bagi setiap konstruk dan item keseluruhan kajian. Secara keseluruhannya nilai alpha bagi pemboleh ubah Penghayatan Akidah ialah $\alpha=0.868$. Bagi konstruk kefahaman $\alpha=0.662$, konstruk perasaan $\alpha=0.910$ dan konstruk amalan $\alpha=0.830$ (sila rujuk jadual 1.4).

Jadual 1.4: Nilai Pekali Alpha bagi Pemboleh Ubah dan Setiap Konstruk

\begin{tabular}{lccl}
\hline \multicolumn{1}{c}{ Pemboleh ubah / konstruk } & Bil item & Pekali alpha & \multicolumn{1}{c}{ Interpretasi } \\
\hline Penghayatan akidah & 90 & $\alpha=0.868$ & Tinggi \\
Kefahaman & 29 & $\alpha=0.662$ & Sederhana \\
Perasaan & 31 & $\alpha=0.910$ & Sangat tinggi \\
Amalan & 30 & $\alpha=0.830$ & Tinggi \\
\hline
\end{tabular}


Ketiga-tiga konstruk penghayatan akidah (kefahaman, perasaan dan amalan) menunjukkan nilai pekali alpha yang berbeza. Berdasarkan nilai pekali alpha yang diperoleh konstrukkefahaman mempunyai nilai pekali alpha yang sederhana $(\alpha=0.662)$ berbanding konstruk perasaan $(\alpha=0.910)$ dan amalan $\alpha=0.830)$ yang mempunyai pekali alpha yang tinggi. Menurut Gable dan Wolf (1993) kebolehpercayaan alpha keseluruhan bagi konstruk mestilah mempunyai nilai sekurang-kurangnya 0.70 tetapi nilai 0.80 ke atas adalah lebih baik. Pallant (2001) pula berpendapat nilai indeks alpha sebanyak 0.7 atau ke atas adalah baik bagi skala instrumen yang mempunyai sepuluh atau lebih item dan nilai alpha sebanyak 0.5 pula dianggap baik untuk skala instrumen yang mempunyai kurang daripada sepuluh item. Oleh kerana konstruk kefahaman mempunyai 29 item, nilai kebolehpercayaan bagi konstruk kefahaman dianggap sebagai kurang baik.

Kajian rintis yang dilakukan menunjukkan kebolehpercayaan bagi pembolehubah penghayatan akidah adalah tinggi $(\alpha=0.868)$. Namun begitu kebolepercayaan bagi konstruk kefahaman $(\alpha=0.662)$ tidak mencapai tahap baik sebagaimana yang disarankan oleh Palant (2001) serta Gable dan Wolf (1993). Menurut Mohd. Najib (2003), nilai $\alpha=0.662$ masih berada pada tahap sederhana. Beliau mencadangkan rintis kedua dilakukan sehingga mencapai $\alpha=0.8$ ke atas. Namun begitu, Kerlinger (1986) dan Mohd.Majid Konting (1990) menyatakan pekali kebolehpercayaan yang lebih daripada 0.60 sering digunakan. Walau bagaimanapun, pengkaji akan melaksanakan kajian rintis kali kedua sehingga nilai pekali alpha meningkat kepada $\alpha=$ 0.8 ke atas. Kajian ini bagi memastikan kebolehpercayaan bagi setiap konstruk adalah tinggi.

\section{Kesimpulan}

Kajian ini melaporkan tentang kesahan dan kebolehpercayaan instrumen penghayatan akidah yang melibatkan tiga domain utama iaitu kefahaman, perasaan dan amalan pelajar terhadap akidah Islam. Definisi konseptual bagi penghayatan akidah diperoleh melalui kajian literatur, perbincangan dengan pakar akidah Islam dan juga merujuk kepada matlamat Pendidikan Islam KBSM. Ia disusuli dengan pembinaan instrumen penghayatan akidah sebanyak 124 item yang mengukur kefahaman, perasaan dan amalan pelajar terhadap akidah Islam menggunakan skala likert. Instrumen ini telah mendapat kesahan gagasan dan kesahan kandungan daripada sembilan orang pakar yang dilantik. Hasil perbincangan dengan pakar, sebanyak 34 item telah dibuang dan 30 item telah dibaiki sebelum ujian rintis dilaksanakan bagi mendapatkan kesahan muka. Keputusan ujian rintis menunjukkan ada satu konstruk dalam kajian rintis tidak mencapai tahap kebolehpercayaan yang tinggi. Antara masalah yang dikenalpasti dalam kajian rintis ini ialah jumlah item negatif yang sedikit, sedangkan ramai pengkaji berpendapat kebolehpercayaan sesuatu konstruk itu boleh menjadi tinggi sekiranya berlaku keseimbangan antara negatif dan positif. Oleh sebab itu, bagi meningkatkan tahap kebolehpercayaan bagi instrumen ini, pengkaji akan melaksanakan kajian rintis kedua. Dalam rintis kedua, pengkaji akan menambahkan jumlah item negatif sebanyak 25\% daripada jumlah keseluruhan item dengan setiap konstruk akan mempunyai jumlah item negatif yang seimbang.

\section{References}

Ab. Halim. 2008. Kajian perbandingan amalan pengajaran guru pendidikan Islam dalam proses pengajaran dan pembelajaran pendidikan Islam. Laporan Penyelidikan. Bangi: Fakulti Pendidikan, UKM.

Ahmad Munawar Ismail. 2009. Pengaruh akidah terhadap penghayatan akhlak pelajar-pelajar sekolah menengah kebangsaan di Malaysia.Tesis Ph.D. Bangi: Fakulti Pendidikan, UKM.

Ary Ginanjar Agustian. 2002. ESQ: Emotional Spiritual Quotient. Jakarta: Penerbit Arga.

Azhar Ahmad. 2006. Strategi pembelajaran pengaturan kendiri pendidikan Islam dan penghayatan akhlak pelajar sekolah menengah. Tesis Ph.D. Bangi: Fakulti Pendidikan, UKM. 
Azma Mahmood. 2006. Pengukuran tahap penghayatan pendidikan Islam pelajar-pelajar sekolah menengah di Malaysia. Tesis Ph.D. Bangi: Fakulti Pendidikan, UKM.

Gable, R. K., Wolf, M. B. 1993. Instrument development in the effective domain. $2^{\text {nd }}$. Ed. Boston: Kluwer Academic Publisher.

al-Ghazali, Abu Hamid Muhamad ibn Muhamad. 2005. Ihya 'ulum al-din. Cairo: Dar al-Tauzi' wa al-Nasyr al-Islamiah.

Hamka. 2003. Kesepaduan iman dan amal soleh. Shah Alam: Pustaka Dini.

Hasan Langgulung. 1983. Psikologi dan kesihatan mental di sekolah-sekolah. Bangi: Universiti Kebangsaan Malaysia.

Hazman Hassan. 2011. Pengaruh satanisme dalam fenomena metal di Malaysia: analisa dari perspektif akidah Islam. Tesis Ph.D. Kuala Lumpur: Akademi Pengajian Islam, UM.

Kerlinger, F. N. 1986. Foundation of behavioral research. $3^{\text {rd }}$ Ed. Orlando: Harcourt Brace Jovanovich College Publisher.

al-Kindi, Abu Yusuf Ya'qub ibn Ishaq. 1980. Risalah al-hilah li daf'i al-ahzan. Dlm. `Abd alRahman Badawi (pnyt.). Rasa'il Falsafiyah. Beirut: Dar Andalus.

Mohd. Arip Kasmo. 2000. Pemantapan akidah menerusi penghayatan sains dalam al-Quran. Tesis Ph.D. Bangi: Fakulti Pendidikan, UKM.

Mohd. Majid Konting. 1990. Kaedah penyelidikan pendidikan. Kuala Lumpur: Dewan Bahasa dan Pustaka.

Mohamad Sulaiman Yasin. 1988. Pengantar akidah. Kuala Lumpur: Dewan Bahasa dan Pustaka.

Noraini Idris. 2010. Penyelidikan dalam pendidikan. Kuala Lumpur: Mc Graw Hill Education.

Othman Mohamad. 2001. Penulisan tesis dalam bidang Sains Sosial terapan. Serdang: Universiti Putra Malaysia.

Pallant, J. 2001. SPSS survival guide. Australia: Allen \& Unwin.

al-Qaradawi, Yusuf. 2005. Iman dan kehidupan. Transl. Fachrudin HS. Shah Alam: Dewan Pustaka Fajar.

Sabiq, Sayyid. 2003. Al-'Aqa'id al-Islamiyyah. Cairo: al-Fath li al-'Ilm al-'Arabi.

Sidek Mohd. Noah. 2002. Reka bentuk penyelidikan: falsafah, teori dan praktis. Serdang: Universiti Putra Malaysia.

Stoner, J., Perrewe, P. L., \& Hofacker, C. 2011. The development and validation of the multidimensional identification scale. Journal of Applied Social Psychology. 41. 7. P:1632-1658.

Wan Noor Afizatun Liza Wan Othman. 2003. Black metal: keruntuhan akhlak di kalangan remaja Islam. Tesis Sarjana. Bangi: Fakulti Pengajian Islam, UKM.

Yahya Ibrahim. 2004. Etiologi masalah sosial: Kajian terhadap remaja di Sungai Petani, Kedah. Jurnal Psikologi dan Pembangunan Manusia. 2004. 20: 47-66.

Yasin, Mohamad Na'im. 1987. Al-Iman, arkanu wa haqiqatuhu wa nawaqiduhu. Kuwait: Maktabah al-Falah. 